\title{
Study on the System of Compulsory Education- Teachers' Management in Mainland China
}

\author{
Bei Lyu \\ Panyapiwat Institute of Management \\ Nonthaburi, Thailand 11120
}

\author{
Kai Shao* \\ Panyapiwat Institute of Management, \\ Nonthaburi, Thailand 11120 \\ *Corresponding author
}

\author{
Weili Huang \\ Panyapiwat Institute of Management \\ Nonthaburi, Thailand 11120
}

\begin{abstract}
Although teachers' mobility system of districtmanagement and school-employment promoted the qualitydevelopment of compulsory education, several problems appeared such as lack-teachers' stability, lack-subjectivity, lack-adaptability and lack-attribution, school culture inheritance as well as arbitrariness, to one's extent, based on the perspective of organizational of management system. Therefore, in order to effectively promote the rational flow of teachers in primary and middle schools, we should establish "file shift" that the regular flow system and build the information sharing platform for teachers, and improve the establishment of dynamic management mechanism and incentive mechanism of educational administration, and then form a series of tracking feedback evaluation mechanism.
\end{abstract}

Keywords - compulsory education period; teachers' mobility; teachers' management system; adaptability

\section{INTRODUCTION}

In order to further response to the call of the Ministry of Education of China and promote the balanced development of compulsory education quality in Jiangsu Province, Nanjing City, implement the flow management system of regional management and school employment in regional district in order to promote the reduction of urban and rural areas and inter school gap, but the flow system of the regional management and school employment has reflects many negative problems after being carried out for 3 years, which can't adapt to the new educational environment, the author will discuss the problems and causes, and put forward some suggestions to further explore the new mechanism to balance the flow of teachers in the new educational environment.

\section{Some Problems IN THE SyStem OF REGIONAL MANAGEMENT AND SCHOOL EMPLOYMENT DURING THE COMPULSORY EDUCATION}

There are mainly two kinds of flows, spontaneous flow and policy flow, included in the regional management and school employment system, the spontaneous flow is proposed by the teachers themselves according to their own will; the policy flow is that the government takes some forcing or encouraging methods to make some teachers or schoolmasters flow from one school to the other for a short or a certain time to promote the balance development of the teachers resources. But, there are some following problems during the process of carrying out this region flow system of teachers.

\section{A. The Conflict between Employment Separation and School-Based Management}

After issuing the policy of regional management and school employment, every district administrative unit set up the "district teacher management center", and carry out "unifying management of personnel files, unifying adjustment of personnel relations, unifying usage of teacher research and unifying train after work step by step", however, it absolutely broke the original personnel bound of the teachers which make the schoolmaster only have the teaching right but don't have the hiring right, it conflicts with the ideas of the school-based management and the schoolmaster-in-charge system promoted in modern school system; besides, some of the flowing teachers taking himself as "system employee" don't follow the management in the flowing school, and negatively undertake the other educational mission except for the teaching. [1]

\section{B. The Conflict between the Flowing Personnel and the Culture of the Flowing School}

To the flowing teachers, they are lack of "school record management" and "safety", and suffer a lot from the certain flowing period, they at least need an adaptive period from a new environment to the other new one, but it is not fair to the student; The flowing teachers are lack of "sense of master" at his new teaching unit, when he goes into a new environment, he need to replace himself which will influent his belonging sense, if he cann't suitably go into the new environment, it's difficult for his to take his "master" responsibility on teaching and other works. Thus, it is easy to know that the teachers only exit on the system flow and they don't 
communicate with others deeply in culture aspect, which not only be shown on that they didn't take part in the research on the school special subject of the flowing school, but also be shown that when the excellent teachers in urban area come to the countryside school at the rural-urban area, it is difficult for them to fit in its environment and culture, which limit the professional development of them and even some of them lag behind.

In speak of the schoolmaster flow, schoolmaster is the core power of one school, the original school will have a sense of 'lost her sole' when her schoolmaster is left, the duty of the original school cann't be finished, but also the self-management right will be lost at a certain degree; the flowing schoolmaster don't have the management right to teachers and assets when he comes to a new school, so he cann't quickly undertake the culture heritage of the flowing school, which only exit on the system exchange, which is not good for the development of soft development of the school, profession development of the teachers and comprehensive development of the students.

\section{The Conflict between the Promotion of the Flowing System and the Whole Understanding Lag of the Teachers [3]}

The core of the regional management and school employment is to break the bound of the allocation of the teacher resource and more effectively promote the excellent and balance development of the school during the compulsory education, further promote the fair and justice of the modern education, which is not the hope of the public but also the needs for the personnel development of each student, from the Education Department to Education Hall and then to Education Bureau, these departments work together with each other and carry out continuously; but the idea and awareness of some teachers only exit on carrying out the system due to the objective and disadvantage reason but ignore the basic mission of educating the people.

\section{The Conflict between the Single Flow and the High Quality Balanced Pluralistic Direction [4]}

In the system of teachers flow, most actively flowing teachers are from ordinary schools and weak schools, their willingness to flow is very strong, they are willing to participate in the flow of teachers, to learn new teaching skills, and desire to get further development in teachers' profession; the policy of the flow of teachers is mainly reflected in the flow from the urban schools to the urban and rural schools and the teachers in good schools flow into the weak schools, in recent 2 years, the brand-name quality schools founded the alliance school, radiate with the same point, this kind of single mode does not communicate with each other to learn from each other, thus it can not take advantage of the special environment of the union school itself which reduce the effect of the policy of the teachers flow at a certain degree and influence the efficiency of the management system of teachers flow.

\section{REASONS FOR THE PROBLEMS IN THE REGIONAL MANAGEMENT AND SCHOOL EMPLOYMENT SYSTEM IN COMPULSORY EDUCATION PERIOD}

There are many reasons which formed the problems during the system of teachers flow, and the most key reason is the management system of the teachers.

\section{A. Effectiveness Lack in the System}

In 1999, the CPC Central Committee and the State Council has clearly proposed in The Decision on Deepening Educational Reform and Fully Promoting the Quality Education that 'all localities should formulate policies and encourage key teachers in large and medium cities to teach or take part-time jobs at the instable schools; teachers in primary and secondary schools in the cities (towns) should teach by various ways in schools in rural areas". In 2003, The Decision on Further Strengthening the Rural Education Work Made by the State Council has pointed out that 'set the service system of the primary and secondary school teachers teach in the rural areas.' In 2006, the Ministry of Education issued The Opinions on Strongly Promoting the Teachers in the Town to Support the Education Work in Rural Areas, and put forward that 'the primary and secondary school teachers in big or middle cities should support the education work in rural area, the primary and secondary school teachers in the counties should regularly teach at the rural area, the high school granulates should support the rural education' and so on. In 2003, at a certain time, it is put forward at The Decision on Future Strengthening the Education Work at Rural Area Made by the State Council that 'set up the service system that the primary and secondary school teachers go to rural areas for supporting teaching work.' The content of these documents is basically focused on a single exchange direction - from excellent to weak; small exchanging subjects-backbone teachers; short-time exchanging. In 2006, the Compulsory Education Law put forward 'the educational administrative department of the country people's governments should balance the teachers resource within their respective administrative are, organize the train and flow among the schoolmasters and teachers,' which write the teachers flow at the county level in the legal document at the first time. In 2010, the Outline of Education Plan has promoted that 'carry out the teachers and schoolmasters flow within the counties (districts) area.' The connotation of the system changes according to the surrounding educational environment, and changes the single direction exchange into two directions.

\section{B. The Absence of Teacher Centered Subjectivity in the System}

There are mandatory phenomenon on the flow of teachers according to the survey of Li Liang belonging to Hubei University of Economics Law Institute [5].35.79\% teachers are flowed through the individual intention, and the flowing autonomy of the remaining $64.21 \%$ the teachers is not in the hands of individual teachers. The rest $20 \%$ are directed by the leaders. This way of choosing teachers to flow is too coercive and has a strong subjective consciousness. One the one hand, the flowed teachers will 
teach with discontent, thus the students will be affected in the acquisition of knowledge; on the other hand, the leaders will have 'selfish', they will specify the flowing teachers and leave the excellent teachers with good experience, teaching ability and good reputation at their own school, and ask some young, lack of experience and teaching ability teachers to take part in the teacher flow activity, then there is a big problem in the fairness and impartiality of the flow, because, on the one hand, the teaching ability of the flow teachers is limited, thus they may not undertake the education work; on the other hand, the flowing teachers just get used to the education work less than 3 years and must leave it which lead a big discount to the flowing effect.

\section{The Lack of Operability of the System [6]}

In the implementation of the teacher flow system, the regulation in the system and actual operation are contradictory, the specific contradictions are embodied in the three major contradictions in the flow of teachers pointed out by Shiwu Xia and Jihai Yao; the first contradiction is currently in the compiling and planning of downsizing for efficiency of our country, no matter the ordinary school or the pubic praise school, 'each teacher has his own task, hire one teacher after 5 ones retired', they all run at full capacity, there is no extra power can be flowed; the 2nd contradiction is existed between the system of 'determine post and organizational structure' and teachers flow, under the system of ' the administrative relations will go together with the teacher himself', the flow teacher will face the problems of deciding the posts and structures, and due to the limited compiling data, the flow school may not provide the same administrative level to the flow teacher which influence the activity of them; the 3rd contradiction is the lack of humanistic care in the flow system, which leads to many family conflicts of the flow teachers. There is a balance between the life and work of the flow teachers, but when they are flowing, the balance will be broken, such as the change on workmate relations, the work unit distance to their home, and raising on children; besides that, according to the research of Professor James of Harvard University in United States: If there is no encouragement, $20 \%-30 \%$ of the personnel ability will be played; if there is encouragement, $80 \%-90 \%$ of the personnel ability will be played [7], the encouragement method from the government is not strong is also a big problem in the implementation of teacher flow.

\section{THE IMPROVEMENT AND OPTIMIZATION MEASURES OF THE SYSTEM OF REGIONAL MANAGEMENT AND SCHOOL EMPLOYMENT IN THE COMPULSORY EDUCATION STATE}

In order to more efficiently promote the flow of teachers, the authors thinks it can be done from the 3 aspects of the top design of the education administrative department, the inclusive growth of the exchanging school, the active cooperation among the flow teachers to form a new set of teachers flow system, which can include the starting mechanism of this system, the choosing mechanism, the reflecting mechanism, the complaining mechanism, the communicating mechanism and the exiting mechanism.[9] Among them, the first three levels are the administrative department of education of the top-level design, which is divided into the national education administration and local education administrative level, the national education administration department should give fundamental incentive policy system supporting the flow of teachers including the starting mechanism of this system (flowing reason, flowing connotation and flowing far meaning). The local education administrative level should give clear regulations on the teachers flow time, teachers flow object, teachers flow ratio, teachers flow type, try best to make the outflow school, influx school, flow teachers, students and communities can get benefit in the system of teachers flow, and also can make them carry out the flow system, follow the 'contract spirit' of this system, which can be specifically displayed on the selecting mechanism (respect the willingness of the teachers, take care of the professional skills of the teachers and the actual demand of the influx schools), title promotion of the teachers, the excitation mechanism, compensation mechanism of the performance-related pay, and long-term follow-up evaluation feedback mechanism of the flow system.

The second is the management of the school employment level, on one hand, the outflow school should take the principle of 'take care the whole situation, do not keep the selfish motion' to choose the teachers resource to restructure the teachers, to emphasize on advise the selecting random and formalism, and be sure to make the best usage of the personnel; on the other hand, the influx school should equally and warmly welcome the new partners to promote the subjective sense of the flow teachers, to actively carry on the campus culture from the flowing school, and to maximize the subjective initiative of the flow teachers. There can be a certain period of running-in time between the flow teachers and school, and actively communicate with the leadership of the school, to increase the in-service training for teachers, and be sure the fairness on the right to know, right to talk, right to complain, the flow school should show their human care to the flow teachers, and properly take care of the objective demands of them and try to do it perfect.

Finally, it is the teacher's application level. The teachers should strive to improve the education consciousness, actively take part in the teachers' flow system and the teachers will have right to know, right to speak at the same time, and be sure carry out the 'contract spirit' of the exchanging system, and the teachers should actively play their role after flowing in the new school, and try their best to undertake the culture (from the system personnel to the school personnel and finally to the owner of the school), and return to the teachers themselves position, actively participate in the class construction of the flow school, and join in the team construction of the influx school under the premise of self-reliance. [10]

In addition, take use of the internet platform to actively build a teacher exchange platform to public the information, from the start mechanism to select mechanism, adjust mechanism, complain mechanism and finally to the exiting mechanism, of the flow teachers, set up the 3rd party tracking evaluation and feedback team for the flow teachers and system, and the team members should be made of the 
educational administrative leaders, the education manager of the school, the representative of the teachers, the representative of the parents, and the representative of the community, and do the processing evaluation via the longterm tracking mode, and try to be perfectly logical and reasonable .

\section{CONCLUSION}

Finally, if you want to make the system of regional management and school employment to achieve people's reasonable satisfaction, you have no choice but start from the top-level design of the administrative department of education, and give policy support, and in additional to the understanding of the school and humanization acceptance, and plus the teacher's own positive response and subjective coordination, then the actual effect of it can be actually carried out, and make this system be carried out better and farther.

\section{REFERENCES}

[1] Baowei Hao. The system arrangement and guarantee of the 'County management \& school employment' $[J]$. Chinese teacher, 2015(8).

[2] Xinjun Xia. From the 'system person' to 'school person': Think on the teachers flow and culture inhabitation[J]. Shanghai Education Science and Research, 2016(9).

[3] Song Li. Problems in the system of county management and school employment and its related optimizing method [J]. Teaching and management, 2016(2).

[4] Yajuan Shi. Problems exiting in the flow of the teachers in the primary and secondary schools and its optimizing measures[J]. Education and research, 2014(9).

[5] Liang Li. The inspiration brought by the teachers flow of primary and secondary schools between the urban and rural areas in South Korea to the current flowing situation of China.[J].Journal of Hubei Economics School (Humanities and social science edit),2016(11).

[6] Shiwu Xia, Jihai Yao. An empirical study on the implementation of teacher mobility policy in compulsory education schools in pilot counties [J]. Teacher education research, 2016 (5)

[7] Shuming Zhao. Research on human resource management [M]. Beijing: Renmin University of China press, 2001.23-26.

[8] Peiliang Jiang. A study on Teachers' mobility mechanism in school district [D]. Shanghai: East China Normal University, 2016.

[9] Yinghong Yu, Delong Dong, Xia Hu. A study of teacher mobility in urban and rural areas and its integrated development mechanism [J]. Education theory and practice, 2013 (31)

[10] Karen Stansberry Beard and Wayne K.Hoy. The Nature, Meaning,and Measure of Teacher Flow in Elementary Schools: A Test of Rival Hypotheses. Educational Administration Quarterly 46(3). 